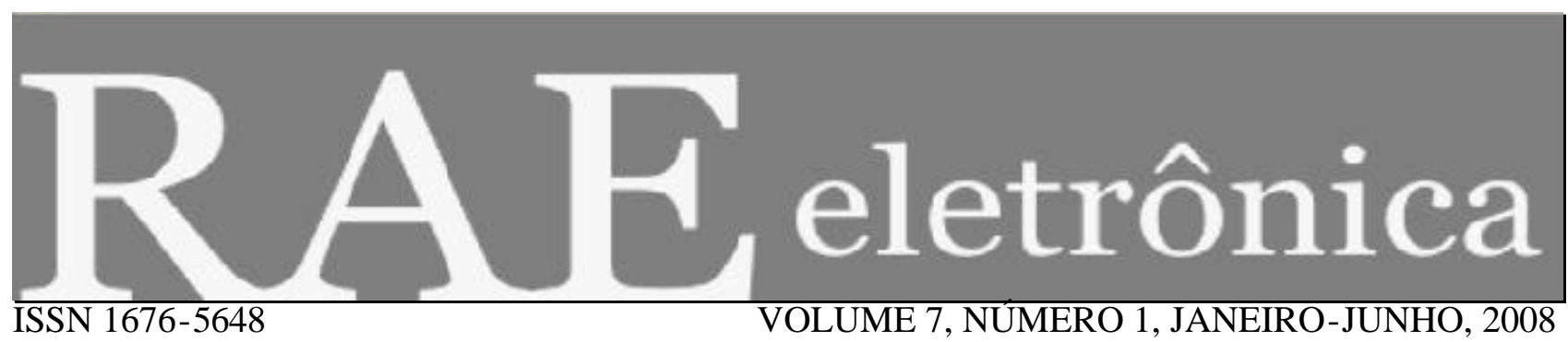

\title{
EDITORIAL
}

A edição de janeiro-junho da RAE-eletrônica apresenta oito artigos nas áreas de inovação, empreendedorismo, estratégia, finanças, gestão internacional e gestão de pessoas.

Gilnei de Moura, Marcelo do Carmo, Rogério Calia e Sandra Façanha fazem uma revisão conceitual sobre redes de inovação e estrutura de relacionamentos inter-organizacionais a partir do estudo de uma empresa de médio porte do setor de metais.

Daniel Fernandes e Cristiane dos Santos apresentam um estudo quantitativo que investiga o efeito da orientação empreendedora na construção da performance empresarial nas organizações. Ainda na área de empreendedorismo, Gláucia Vasconcelos Vale, John Wilkinson e Robson Amâncio debatem o conceito de atividade empreendedora no mundo contemporâneo.

$\mathrm{Na}$ área de estratégia, Vilmar Antonio Tondolo e Cláudia Bitencourt analisam um complexo portuário como um recurso disponível a cooperativas do setor de agronegócios utilizando a visão baseada em recursos $(\mathrm{RBV})$.

Em finanças, Paulo Alvarez e Ricardo Leal apresentam um novo benchmark para o estudo do desempenho de fundos, o Índice de Renda Fixa de Mercado (IRF-M).

Ligia Maura Costa faz, em gestão internacional, uma análise comparativa dos códigos de Conduta de Responsabilidade Social (CRS) de empresas de gás e petróleo na prática contra a corrupção.

Em gestão de pessoas, Anderson Sant'Anna investiga até que ponto a demanda por profissionais dotados de competências abrangentes é acompanhada por uma evolução de políticas e práticas organizacionais de gestão, e Carmem Ligia Grisci estuda as mudanças do modo de controle do trabalho por meio de um estudo de caso em uma instituição bancária portuguesa.

Completa a edição uma resenha de Marcos Avó sobre a nova geração de pesquisas sobre empresas familiares. Em suma: leitura variada, para administradores de todos os tipos. 
Boa leitura!

\section{Francisco Aranha}

Diretor e Editor

\section{RAE-eletrônica}

ISSN 1676-5648

(C)2008 Fundação Getulio Vargas - Escola de Administração de Empresas de São Paulo.

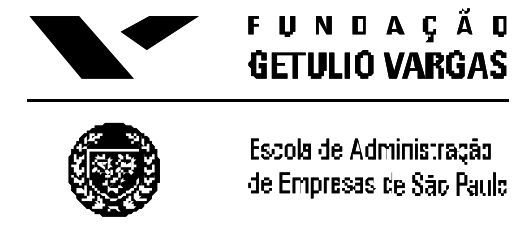

